\title{
Informação, um bem público, direito do cidadão!
}

Eugênio Bucci, paulista da cidade de Orlândia, 46 anos, jornalista, doutor em Comunicação, é o atual presidente da Radiobrás, cargo de confiança do governo brasileiro. A Empresa Brasileira de Radiodifusão, fundada em 1975, atualmente denominada Empresa Brasileira de Comunicação, é uma empresa de administração indireta, vinculada à Secretaria de Comunicação de Governo e Gestão Estratégica. O Sistema Radiobrás tem por objetivo universalizar o acesso à informação sobre o Estado, o governo e a vida nacional. Seu atual presidente, Eugênio Bucci, fala-nos dos esforços para garantir o direito democrático à informação, das diferenças de objetivos da comunicação pública e da comunicação comercial. Apresenta-nos também os avanços conquistados em sua gestão e ressalta a importância da Agência Brasil, a criação da Associação de Rádios Públicas e da TV Brasil, canal integração. A TV Brasil tem por objetivo veicular conteúdos em português e espanhol para toda a América do Sul e parte da América Central.

Por Roseli Fígaro

C \& E: Você é graduado em Jornalismo, cursou Direito e doutorou-se em Comunicação pela ECA-USP. Trabalhou em grandes empresas de comunicação, exerceu até cargo de secretário editorial. Fale dessa experiência e dos desafios que você encontrou no exercício do jornalismo em grandes empresas.

Eugênio Bucci: Fiz minha carreira na Editora Abril. Comecei como repórter de Veja e depois passei para outras áreas. Trabalhei um período na Editora Brasiliense e também no jornal Leia Livros. Em seguida, fui para uma empresa do grupo Abril, a Editora Azul, onde trabalhei com a revista Set - fui diretor dela - e mais tarde com a revista Playboy. Estive na direção da revista Superinteressante. Portanto, minha experiência com uma grande empresa de comunicações é toda dentro da Editora Abril. Colaborei com outros veículos como colunista. Na Folha de S. Paulo, fui articulista e desempenhei outras atividades, mas nunca fiz parte do corpo de funcionários. É importante ter em mente, quando se fala de empresas de comunicação no Brasil, que muito da nossa cultura de jornalismo vem da experiência dessas grandes empresas, e isso tem um valor enorme. É comum sentirmos em faculdades de jornalismo e em certos círculos uma tentativa de se opor o jornalismo às empresas jornalísticas. No entanto, no Brasil, na Inglaterra, na França e, principalmente, nos EUA, os cânones do jornalismo se desenvolveram no exercício da profissão dentro dos marcos das grandes empresas jornalísticas. Vêm desse exercício muitos dos pilares que são 
paradigmas para essa profissão. É claro que há, hoje, uma referência importante que provém da experiência de empresas públicas como a BBC, por exemplo. Mas não há incompatibilidade entre o interesse empresarial e o exercício do jornalismo. Certa incompatibilidade pode aparecer no desenvolvimento da profissão; há mesmo casos em que surge uma contradição entre a vocação de certas empresas de comunicação e as bases da democracia fundamental para o exercício do jornalismo. Isso já se verificou em alguns países da América do Sul, e persiste. Mas, na origem, essa contradição não existe. Nesse sentido, o que posso dizer é que a Abril foi uma grande escola de jornalismo. Vi ao longo do tempo condutas exemplares e observei como os fundamentos dessa profissão podem, devem e efetivamente são cultivados em grandes empresas.

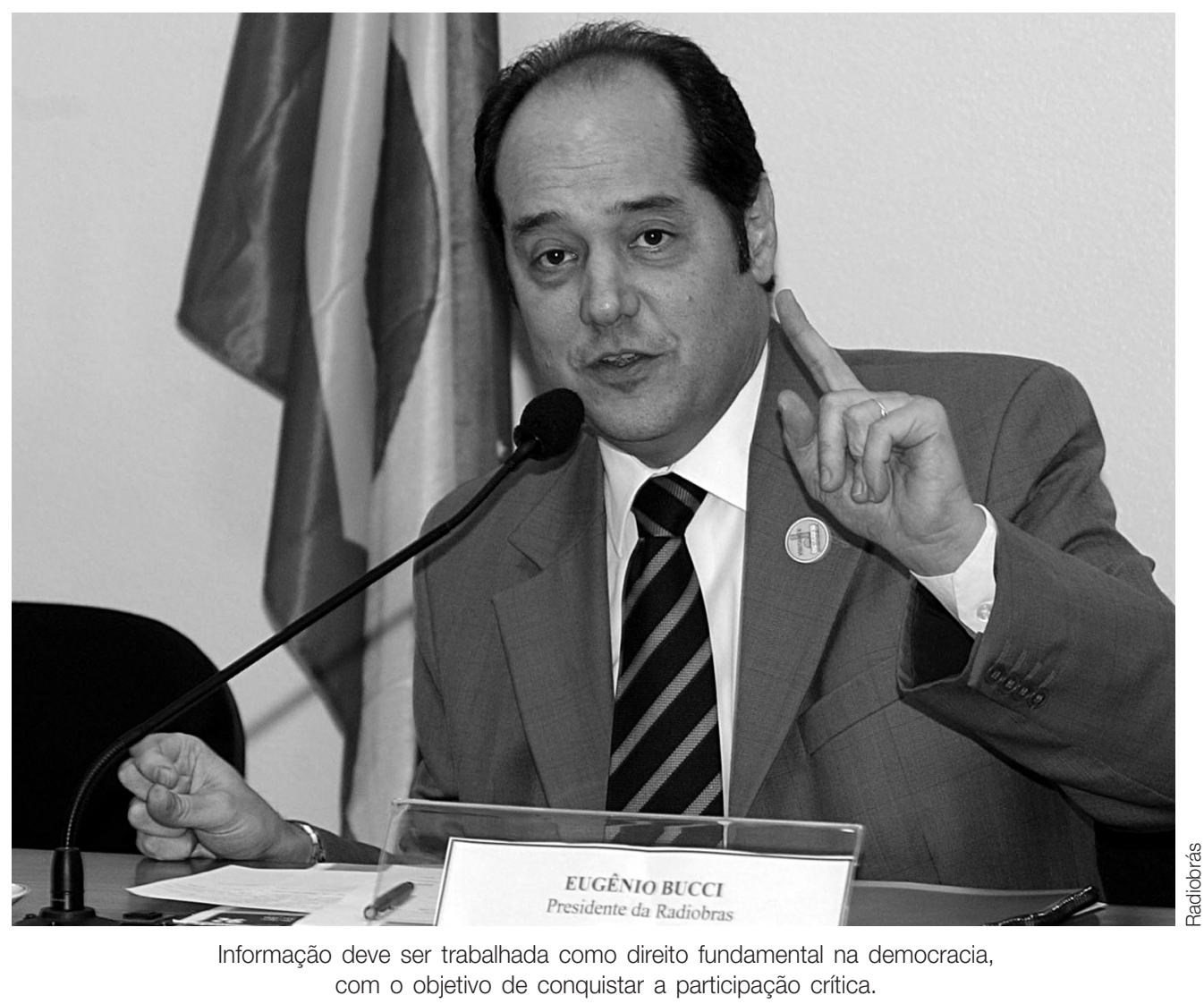

C \& E: E a escola, você acha que tem um papel na formação do jornalista? Você também foi professor...

Eugênio Bucci: Fui professor e isso que estou falando, sobre as grandes empresas jornalísticas, pode suscitar erroneamente a impressão de que toda a base teórico-conceitual para o exercício da profissão pode ser forjada dentro da empresa, e isso não é verdade. Essa base não pode ser encontrada na empresa. O jornalismo precisa da formação que lhe chega da cultura, das ciências, das letras. Esse é um fato verificável em qualquer sociedade democrática. Todos sabemos que, quando surgiu o jornalismo, semente da instituição da imprensa atual, no período das grandes revoluções dos séculos XVII e XVIII, ele foi 
povoado pelas influências da Literatura, da Filosofia, das Luzes, da Razão. Os filósofos eram jornalistas e os escritores também. Depois dessa origem, a presença da universidade, no seu sentido mais alto, se torna indispensável, porque as redações são centros de processamento de informação. O discernimento sobre a seleção da informação tem parte com o mundo do conhecimento, e para um jornalista e para uma equipe jornalística saber pensar com autonomia requer contemporaneidade, vivência, atualização permanente e capacidade de identificar tendências. Ora, isso não se aprende na prática. Aprende-se no contato com a teoria, com a pesquisa, e isso só a universidade pode suprir. Sei que muitos argumentam que há ótimos jornalistas que nunca passaram pela universidade. É evidente que existem, mas eles foram mais freqüentes na fase anterior da tradição jornalística brasileira. Tivemos o Mário Pedrosa, que foi um intelectual de ponta e que não passou pela universidade; e também o Cláudio Abramo, de quem inclusive lembro uma passagem muito curiosa. Uma vez ele foi chamado para dar aulas na Escola de Comunicações e Artes e apresentou um currículo de meia página! Figuras como eles, que não passaram pela universidade, vão se tornando mais escassas e as figuras de ponta do jornalismo que estiveram na universidade vão se tornando mais dominantes; essa é uma tendência. Cada vez mais o contato com a universidade será um fator de qualificação e de capacitação, de atualização dos profissionais da imprensa.

C \& E: Já ouvi você dizer que o jornalista é um mediador social. Será que o jornalista tem dimensão do que seja a responsabilidade de ser um mediador social?

Eugênio Bucci: É muito difícil generalizar e estabelecer uma medição do que seja a consciência da responsabilidade do jornalista. De maneira geral falemos do comunicador, porque há comunicação social de amplo alcance nos meios eletrônicos e funções que não são desempenhadas por profissionais do jornalismo. Aqui não vai nenhuma consideração de ordem corporativa, é apenas uma observação. Um animador de programa de auditório, por exemplo, é um comunicador social com um poder enorme e ele acaba cumprindo, mesmo quando não tem consciência, um papel educativo, o papel de hierarquizar valores. É engraçado pensar nisso, mas muitas vezes um animador de programa de auditório exerce a mesma função que um padre exercia no século XVIII, falando o que é certo e o que é errado. Muitos animadores fazem isso, separando o conveniente do inconveniente, o que é aceitável do que não é aceitável... As celebridades têm opiniões sobre qualquer coisa e as pessoas consomem essas opiniões, sobretudo das celebridades. Essa questão da responsabilidade dos comunicadores é muito mais ampla do que o exercício do jornalismo. Mas também aparece na atividade jornalística. Vivemos um tempo em que jornalista é símbolo sexual, é celebridade ou, pior ainda, pode aspirar a ser celebridade. Tais componentes trazem para o profissional responsabilidades sobre as quais ele deveria pensar. Quando falamos de responsabilidade do jornalista é evidente que o exame permanente dessa condição ajudaria o exercício da profissão, bem como auxiliaria a gestão das empresas encarregadas da comunicação social. É 
comunicação \& educação • Ano XI • Número 3 • set/dez 2006

claro que a democracia avançará se nos relacionarmos mais criticamente com a ação desses meios. Essa consciência crítica capacitaria o público e os operadores dos meios de comunicação. Tal responsabilidade do jornalista é proporcional e relacionada com a consciência geral da sociedade sobre o papel da comunicação. Uma coisa requer a outra, ou pressupõe a outra, e isso tem a ver com a defesa da democracia.

C \& E: Você quer dizer que cabe também ao cidadão comum entender que ele tem direito à informação, à notícia e que ele deve se orientar com certa autonomia. O jornalista tem papel nisso?

Eugênio Bucci: Essa pergunta é ótima porque traz à cena a necessidade de que o jornalismo seja controlado pelo público. Não me entenda mal, não estou dizendo controlado pelo Estado ou por qualquer organismo em nome do Estado. Digo controlado pelo público, e isso não significa ter parte com o cerceamento de liberdade. É o controle do público, aos olhos do público, sobre qual é o jornalismo que serve à população e sobre qual não serve, sem aplicação de sanções, sem restrição à liberdade... isso nunca! Há percepção de que ao próprio jornalismo interessa a presença do público como demandante de qualidade. E essa é uma tendência já bastante corporificada, que se manifesta, por exemplo, na presença do ombudsman. A Folha de S. Paulo realizou, em 2006, um evento internacional com a presença de vários profissionais que exercem a função de ombudsman nos jornais. Outro exemplo é o Observatório da Imprensa, do Alberto Dines, que completou dez anos recentemente. O Observatório é criticado, é elogiado, mas fundamentalmente tem o mérito insubstituível de ter posto a discussão do jornalismo em público, lavando roupa suja da imprensa de janela aberta, diante do público.

C \& E: Importante é garantir o nível da discussão com transparência...

Eugênio Bucci: É claro. Existem também outras iniciativas. Há, por exemplo, o Intervozes, uma entidade recente, com cerca de um ou dois anos. Congrega jovens jornalistas que atuam no sentido de interferir na mídia para abrir espaço de debate, para democratizar a informação. Se observarmos, encontraremos inúmeros sinais que concorrem para trazer a presença do público para o debate da qualidade do jornalismo. O ombudsman é um ótimo exemplo, porque ele ouve o leitor do jornal, transforma o que ouve em matéria desse mesmo veículo e analisa, a partir disso, o comportamento do jornal. Esse exercício torna o público um agente de controle, no melhor sentido da palavra. Sem dúvida, a consciência do público impacta a consciência do jornalista e as pessoas vão percebendo que essa profissão só tem futuro se estiver a serviço do público.

C \& E: Vocêe ó a atual presidente da Radiobrás e já deve ter ouvido esta pergunta muitas vezes, mas gostaria que você esclarecesse qual a diferença entre empresa pública e empresa estatal. Eugênio Bucci: Em primeiro lugar, essa é mais uma posição que exerço e que comporta um enorme risco. Aceitar o cargo de presidente da Radiobrás, com 
o histórico de uma carreira de jornalista independente e de não-engajamento profissional partidário, é um risco, porque a tradição dessa instituição é a de não prestar informação objetiva e independente, mas de funcionar como extensão da lógica de propaganda de governo. Em segundo lugar, o risco estaria na possibilidade de o meu trabalho não acrescentar nada àquilo que já estava dado, tamanhas são as restrições culturais que estão postas. É muito difícil...

\section{C \& E: A força da máquina...}

Eugênio Bucci: É a força da inércia e a força de requisição que vem do aparato de Estado, habituado a uma relação dada e que mais ou menos funciona. Há o risco de se ir para um lugar desse e não se fazer diferença nenhuma, ser simplesmente neutralizado, anulado pela máquina. Há outros fatores de risco, mas correr risco faz parte. Lembro-me de, ao aceitar o convite para trabalhar na Radiobrás, na despedida da coluna que fazia na Folha, escrever que conhecia o jornalismo independente do Estado e que ia para esse novo desafio querendo conhecer o jornalismo independente do Capital, se é que esse jornalismo pode existir. Gostei de ter feito esse desafio para mim mesmo em público e ele me animou durante um bom tempo. Agora tenho tranqüilidade, pois atualmente na Radiobrás se pratica jornalismo independente; jornalismo que noticia vários eventos e fatos importantes do interesse do cidadão e não necessariamente de interesse da promoção do governo. Noticiaram-se fatos, inclusive, que, para uma análise imediatista de visão estreita, pareciam vir de um jornalismo de oposição. Ficou provado que não é nada disso. Criaram-se elementos de uma nova cultura, ainda em fase inicial, que busca objetividade, substância na apuração e na edição de informações em rádio, televisão e internet. Informações que atendam ao interesse e ao direito do cidadão naquilo que faz diferença direta na vida dele.

Alguns observadores diziam, com a melhor das intenções, que a Radiobrás havia publicado, no rádio e na TV, coisas de oposição ao governo. Não vou citar quem falava isso porque, como eu disse, foram comentários que ouvi, não com a intenção de destruir o que estávamos fazendo, não com o propósito de me pressionar, mas eram comentários de avaliação num diálogo franco, aberto, até amigo. Existe a visão, ainda arraigada na prática política brasileira e na administração pública brasileira, segundo a qual a comunicação é sempre uma ferramenta de convencimento. Ela é concebida como um instrumento para

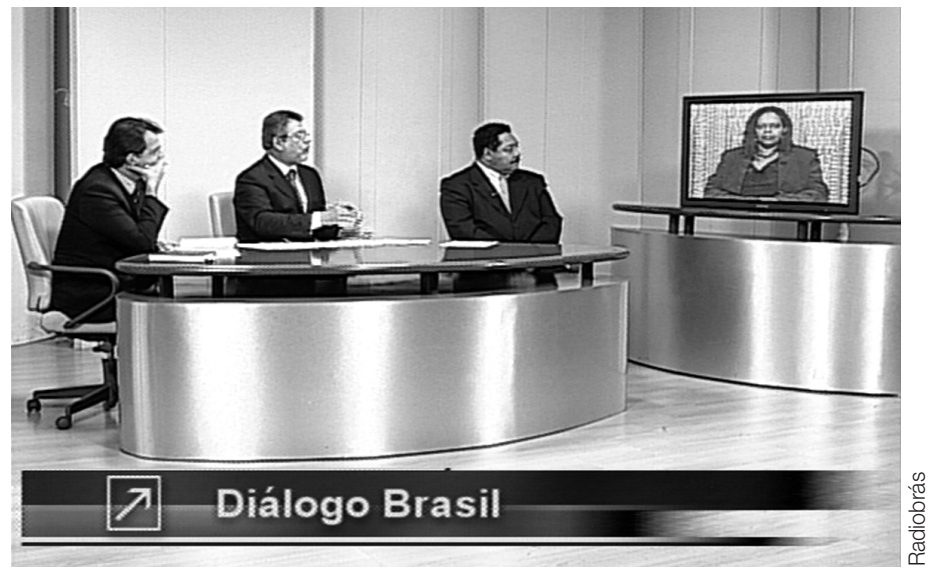

Diálogo Brasil discute, ao vivo, temas de interesse para o País. Exibido todas as quartas-feiras, às 22h50, é produzido e transmitido pela TV Nacional e integra a grade da Rede Pública de Televisão. 
comunicação \& educação • Ano XI • Número 3 • set/dez 2006

dirigir a formação da opinião e da vontade da sociedade, em prol das causas que o governo abraçou. Raramente a comunicação é compreendida como um ambiente que não pode ser dirigido por um interesse partidário, e mais do que isso, como um ambiente que propicia atender ao direito à informação. E esse é um direito tanto para os que pensam contra quanto a favor do governo. A informação é um direito. Ora, se existe sentido em haver uma rádio pública é porque existe carência de informação, e é preciso atender a esse direito. Portanto, a emissora só pode ser administrada para atender o cidadão; ela é um bem público, não um bem particular do governante. Durante muito tempo, aceitamos como normal que esses espaços fossem vulneráveis ao interesse partidário e às vezes até ao interesse familiar. Quando alguém olha uma notícia publicada pela Radiobrás e pensa inocentemente que aquela informação não ajuda o governo, está pensando a partir de uma matriz ultrapassada, uma matriz patrimonialista. Ao contrário, deveria pensar que a informação é fidedigna, atende aos requisitos da precisão, da objetividade, é uma notícia de interesse do cidadão e, portanto, o governo prestou um bom serviço. Se o governo é o proprietário daquela empresa e prestou um bom serviço, esse é um trabalho positivo porque aquela instituição pública cumpriu a sua função de informar com objetividade, atendendo a um direito... isso é bom para o governo. Numa democracia, o governo não pode ter uma comunicação para conquistar adesão, concordância e obediência. Esses eram os objetivos da comunicação na ditadura e se alongaram por um bom período. Na democracia, toda comunicação que esteja porventura sob a supervisão de qualquer governo deve ter como objetivo conquistar a participação crítica. Na sociedade democrática, até a divergência é um fator da coesão social, porque a convergência e a divergência implicam o compromisso de participação social. Essa transição do modelo de comunicação da ditadura para o modelo da democracia é sofrida, penosa, não é fácil de ser feita e nós ainda não a fizemos completamente no Brasil.

\section{C \& E: Você tem chamado esse tipo de exercício profissional de comunicação pública?}

Eugênio Bucci: Sim. Comunicação pública é uma expressão genérica e muito usada. É a comunicação que está a cargo, por uma razão ou por outra, dos poderes da República. Às vezes por meio de uma fundação que recebe verbas, ou de uma assessoria, como é o caso do Supremo Tribunal Federal, ou de uma empresa pública, como é o caso da Radiobrás. A Radiobrás é uma empresa de direito privado, da administração indireta. Ela não é, portanto, máquina de governo. É uma empresa de propriedade do Tesouro Nacional, regida pela Lei das Sociedades Anônimas; os seus funcionários são contratados segundo a CLT. É uma empresa pertencente ao poder público, mas não é regida pela administração direta; tem os seus gestores, os seus administradores, capazes de praticar todos os atos relativos à gestão com a devida autonomia. Comunicação pública é um termo genérico porque denomina uma série de atividades: relações públicas de governo ou de instituições ligadas ao governo, assessoria de imprensa, publicidade de governo e empresas que praticam a radiodifusão. 
Informação, um bem público, direito do cidadão! • Roseli Fígaro

A radiodifusão, aliás, é uma função pública e requer o cumprimento de uma série de obrigações, seja ela exercida por uma empresa do Estado, seja por uma empresa da iniciativa privada, pois a concessão é pública.

C \& E: Se pensarmos em comunicação pública como um conceito, nós podemos pensar em comunicação privada?

Eugênio Bucci: É por isso que o termo é complicado. Podemos pensar em comunicação comercial, por exemplo. Podemos falar em comunicação presidida pelos imperativos de captação de recursos no mercado anunciante com finalidade de dar visibilidade às mensagens publicitárias. Em oposição a essa comunicação, existe a comunicação pública que não é presidida pela captação de recursos ou pela meta de captar recursos no mercado anunciante. Por essa razão, sou pessoalmente contrário a que emissoras públicas e educativas captem recursos no mercado anunciante, disputando anunciante com a iniciativa privada. Se não se tomar cuidado, cria-se uma competição desleal, porque a emissora pública, além de receber recurso do Estado, vai disputar anunciante com a empresa privada.

C \& E: Será que a empresa pública de comunicação que capta recursos no mercado perde a sua função social, como paradigma dessa comunicação pública? Por que ela existe se ela depende do mercado?

Eugênio Bucci: Concordo com você e até já escrevi sobre isso. O problema de uma empresa pública que vai para o mercado buscar anunciante de mercadorias é que ela acaba caindo na vala comum, disputa com a emissora comercial o dinheiro do anunciante. E, para atender o anunciante, reproduz a linguagem das emissoras comerciais que são hegemônicas. Fato que pressupõe dizer que a empresa pública de comunicação terá um ritmo de intervalos comerciais e uma política de distribuição de programas que respondam a critérios como audiência e apelo emocional para poder dar retorno aos anunciantes. Ela precisará promover o anúncio, a publicidade e, ao fazer isso, começará a funcionar quase como uma emissora comercial. A emissora comercial talvez não possa pôr na sua programação 24 horas de programação de prestígio de cultura, ou educativa, embora tudo que se faça na comunicação social tenha alcance educativo (para o bem

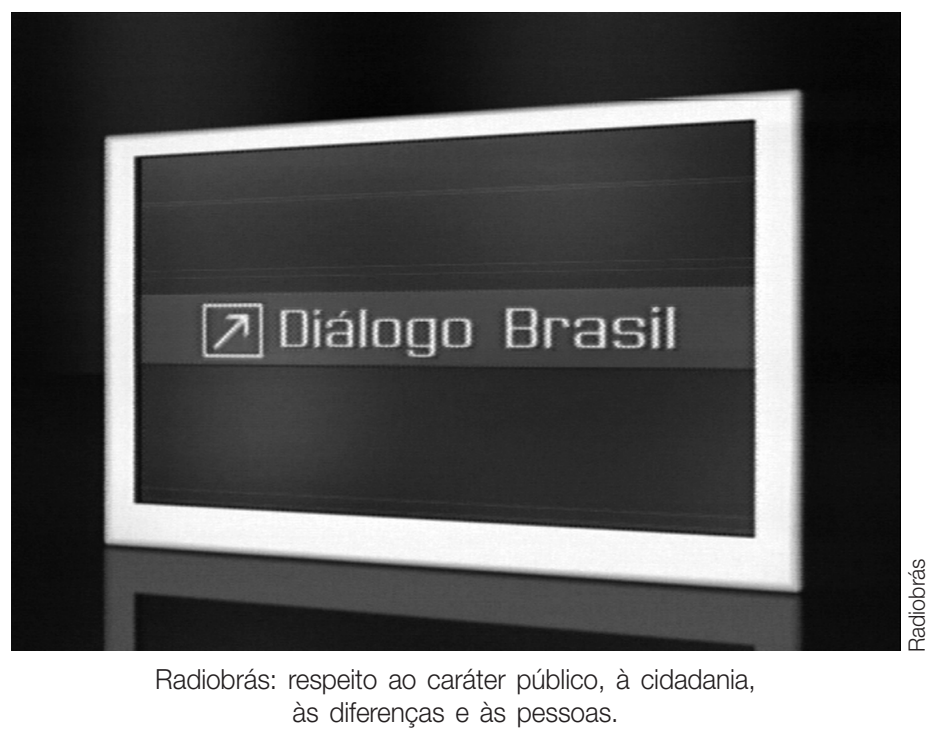


1. Laurindo Leal Filho é sociólogo e jornalista. Professor do Departamento de Jornalismo e Editoração da Escola de Comunicações e Artes da Universidade de São Paulo, fundou e presidiu a ONG Tver, voltada para o acompanhamento da qualidade da televisão brasileira. (N.E.)

e para o mal). Quem sabe não possa mesmo fazer isso. A emissora comercial tem programas de grande apelo, dentro das leis do espetáculo. Sabemos o que representam esses programas. É a emissora pública que pode ter um papel diferenciado na difusão da cultura de acesso mais difícil, que não rende uma audiência muito alta, mas, se for bem-feita, rende alguma audiência. Se a emissora pública precisa prestar contas a anunciantes, vai se distanciando dessa função. Programas educativos atendem ao interesse de uma parcela pequena do público, e isso justifica a existência da emissora pública. Por isso, todas as democracias têm sistemas complementares: de um lado a comunicação pública, de outro a comunicação comercial. Há pessoas que pensam diferente - e eu as respeito muito -, mas acho ruim ver a emissora pública se igualando à emissora comercial.

C \& E: Tratar a informação como um direito do cidadão e inverter o processo, já quase sedimentado, de uma determinada cultura patrimonialista, não é exercitar a criação de um novo parâmetro que possa reger e também regular a comunicação como um direito com regras claras também para a empresa comercial?

Eugênio Bucci: Buscar atender ao direito à informação na empresa pública de comunicação acaba influenciando a comunicação das emissoras privadas. A emissora pública difunde questões e preocupações que também fazem contato com o mundo da comunicação da empresa comercial. O humor da sociedade em relação a isso registra essas questões de um jeito diferente e vai acabar batendo no jornalismo da empresa comercial convencional, na idéia de publicidade da empresa comercial, nos padrões de entretenimento dessa empresa, porque a sociedade terá evoluído nessa direção. O mesmo acontece com relação aos operadores da comunicação, os jornalistas e os outros profissionais. Eles precisam, para melhorar, de que o público esteja engajado na fiscalização e na vigilância. Não é à toa que o Observatório da Imprensa, por exemplo, é veiculado por emissoras públicas, mas tem um impacto grande na cultura das redações das emissoras privadas. A Radiobrás acabou de lançar um programa chamado Ver TV, apresentado pelo Laurindo Leal Filho ${ }^{1}$, em parceria inclusive com a TV Câmara, exibido todas as quintas-feiras, às 22h30, pela TV Nacional de Brasília, NBR, e será transmitido também pela TV Educativa da Bahia. É uma discussão que acontece com mais naturalidade na emissora pública, mas acaba dialogando com o jornalismo e com os programas da empresa privada, inclusive vários dos convidados do Ver $T V$ vêm de televisões de empresas privadas. Mas de fato há uma inversão, como você bem apontou. $\mathrm{Na}$ origem não há contra-

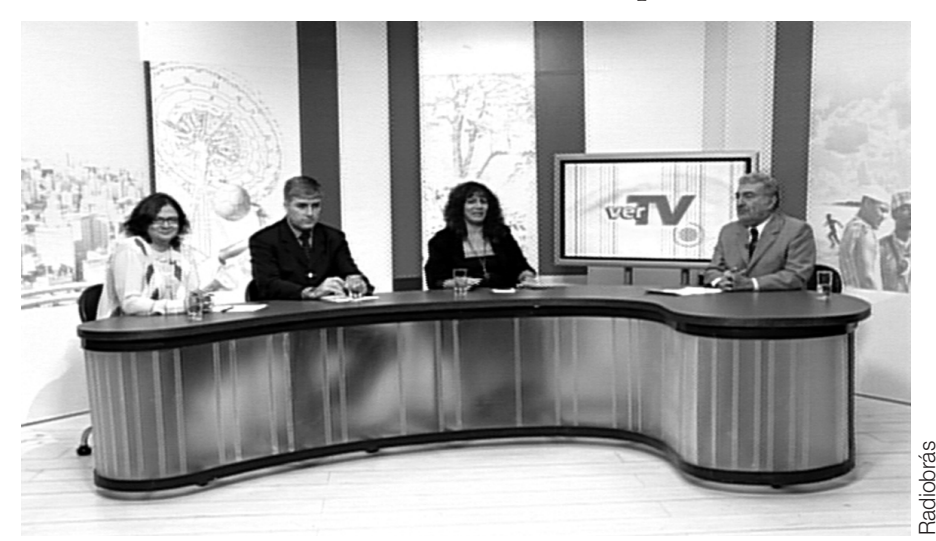

O Ver $T V$ leva ao ar semanalmente três especialistas da área para dar mais visibilidade àqueles que são os dois eixos do programa: a democratização da comunicação e a ética na televisão. 
dição entre a empresa jornalística privada e a prática do melhor jornalismo. Não só não há contradição como o bom jornalismo nasceu fora do Estado. E isso tem sentido porque o jornalismo, entre outras coisas, tem de vigiar o poder e, nos séculos XIX e XX, o poder estava no Estado. Hoje há elementos de inversão que precisam ser considerados. Um exemplo é a seguinte pergunta: por que a cobertura da Guerra do Iraque, pela BBC da Inglaterra, foi mais precisa ou vista como sendo mais objetiva e mais crítica do que a cobertura do mesmo evento feita pelas redes comerciais de televisão dos EUA? No caso, os dois países estavam em guerra no Iraque. Havia a presença de tropas britânicas e tropas norte-americanas, as condições eram muito parecidas. Por que uma televisão pública, que é mantida com o dinheiro do telespectador - o qual é obrigado a pagar por uma lei de Estado, portanto uma emissora sustentada pela ordem legal -, por que essa emissora pública faz um jornalismo mais independente do que o jornalismo feito pelas emissoras privadas? Essa questão é sintoma de um novo paradoxo; um paradoxo que não aparecia antes. Então, em alguns momentos surge um pólo que contém certa contradição entre a melhor aspiração do jornalismo e a condição de sua produção na empresa privada. Por quê? Avançando um pouco, percebe-se que existe um tipo de promiscuidade de escala superior, vinculando interesses presentes no governo, o que não quer dizer interesses de governo, normalmente interesses privados representados ou materializados nessas empresas privadas.

C \& E: As chamadas licitações, por exemplo?

Eugênio Bucci: Não só as licitações. No caso da invasão do Iraque, vamos identificar interesses comerciais muito mais profundos do que os interesses comerciais desse setor em particular; são alianças de interesse que mobilizam estruturas de poder. Isso pode explicar o paradoxo ao qual estou me referindo, e que vem sendo amplamente debatido nos EUA. Esse modelo não é restrito só às redes de TV. Nós tivemos casos importantes envolvendo o Washigton Post, por exemplo, e até alguns fatos do New York Times. Por que houve essa promiscuidade, gerando efeitos na pauta e na qualidade editorial desses veículos?

C \& E: Isso é uma boa investigação.

Eugênio Bucci: É um tema para investigação e é um tema novo. Posso estar dando a entender que já tenho uma conclusão sobre isso, mas não tenho. É um tema novo, que requer uma análise acurada.

C \& E: Cabe a questão sobre a relação das grandes corporações transnacionais e seus interesses comerciais.

Eugênio Bucci: Exatamente...

C \& E: Você tratou da característica da programação das empresas de comunicação e do que seria o papel da empresa pública na defesa de um bom jornalismo para o cidadão. E o entretenimento, é tarefa também da Radiobrás?

Eugênio Bucci: Temos uma discussão sobre o não-uso da palavra entretenimento. Não usamos a palavra entretenimento nos nossos planos estratégicos, 
comunicação \& educação • Ano XI • Número 3 • set/dez 2006

na gestão da empresa e na designação de qualquer atração que seja veiculada pela Radiobrás. Não a utilizamos porque, em nossa compreensão, em nenhum momento a função dos veículos públicos é entreter.

\section{C \& E: Qual o problema de entreter?}

Eugênio Bucci: Há um problema com essa palavra. A emissora pública pode e deve buscar ser agradável. Pode e deve buscar ser divertida, talvez até recreativa; esta é uma palavra que poderia ser empregada, mas a palavra entretenimento não nos serve. Uma programação cultural pode abrir horizontes, pode levar prazer à audiência, pode conduzir a uma experiência estética marcante, mas não deve ter parte com o entretenimento. $\mathrm{O}$ verbo entreter virou uma atividade do nosso tempo industrial. Não há mais como se falar de entretenimento sem que isso carregue o sentido de uma indústria. $\mathrm{O}$ entretenimento é uma indústria de produção que privilegia a veiculação de mensagem publicitária, não é mais outra coisa. Não se pode mais dizer que haja uma montagem de programas de entretenimento cujo interesse não esteja explicitamente vinculado aos interesses comerciais. Entretenimento é um gênero de comunicação montado para vender. A comunicação pública, não sendo uma comunicação destinada a vender, não pode fazer entretenimento. Não é uma palavra neutra, não é uma palavra sem carga ideológica, como ensinaria Bakhtin [Mikhail Bakthin]; é uma palavra que designa em si mesma a adesão a uma indústria. A comunicação pública não é um veículo de entretenimento, mas um veículo, na melhor das hipóteses, de alerta à indústria do entretenimento. Ela está em outro campo... o emprego dessa palavra implica adesão a um campo do qual a comunicação pública não pode fazer parte.

C \& E: Construir informação objetiva demanda critérios claros para a pauta, requer diversidade de fontes, apuração rigorosa, processos de edição claros, critérios de noticiabilidade bastante explícitos, e exige que o profissional tenha muito discernimento ao utilizá-los. Como são tratados os critérios de objetividade e noticiabilidade na Radiobrás? Vocês estão criando um novo parâmetro? Como é isso?

Eugênio Bucci: Não, nós não estamos criando um novo parâmetro. Seria descabido falar nesses termos. Quando digo nós, não estou usando o plural majestático, mas me referindo a uma equipe: eu, o Celso Nucci, que é um talento, um orientador essencial de todo o trabalho realizado na Radiobrás e uma das maiores autoridades que já conheci em planejamento editorial; estou falando do José Roberto Garcez, que é o nosso diretor de jornalismo; estou falando de Helenise Brant, que é a responsável por uma série de programas na Radiobrás; estou falando do Rodrigo Savazoni; enfim, de um time de pessoas - e temo aqui esquecer algum nome - que assumiu o desafio de pensar em que termos poderíamos atuar para contribuir com o atendimento do direito à informação do cidadão brasileiro. Claro que o termo objetividade é complicado. O que significa uma informação objetiva? Você nos dá os elementos que nos ajudam a defini-la. Mas uma coisa importante deve ser dita: nós usamos informação objetiva ou jornalismo com informação objetiva como sendo aquele relato que decorre do objeto, que se prende à descrição empírica do fato, com muitas 
imprecisões, porque essa objetividade, no limite, é facilmente identificada e demonstrada como algo que não existe, mas é melhor do que algo despudoradamente subjetivo e enviesado. Poderíamos usar o adjetivo neutro, mas o neutro é um termo que traz prejuízos, uma mistificação quase de má intenção, porque a neutralidade é impossível. Todo discurso é formulado por um sujeito. Nós temos claro que o sujeito que fala está comprometido com o atendimento ao direito de informação. O nosso discurso é inteiramente direcionado ao atendimento desse direito e, mais do que isso, definido pelo seu propósito. É o propósito do direito à informação que o define e ele caminha para o cumprimento desse fim. Por isso, tem a identidade de vetor. Não é de onde ele vem, no sentido clássico, mas é para onde vai que o define. Nosso trabalho se dirige ao cidadão para cumprir o direito à informação, e é o direito à informação que o sustenta; nós somos servidores desse direito à informação.

C \& E: Pensando assim, a partir desse vetor, as fontes privilegiadas mudam de definição? Eugênio Bucci: Totalmente. Nós brincamos que adotamos o método Paulo Freire na nossa comunicação. Paramos de adotar o que era tradicional na Radiobrás, o linguajar de relatório técnico, de nota técnica, o administrativês. Passamos a adotar a linguagem daquele para o qual se destina a nossa comunicação. $\mathrm{O}$ protagonista da notícia muitas vezes deixa de ser a autoridade que assinou um papel qualquer e passa a ser o cidadão que vai poder assumir uma tática diferente a partir daquele momento, porque se o papel que a autoridade assinou não mudar materialmente a vida daquele que está lá na ponta, então isso não será notícia para nossa pauta e nós não a noticiaremos...

C \& E: Você está dizendo que reescreveram um dos critérios de base do que é notícia, ou seja, sobre a notoriedade e autoridade da fonte?

Eugênio Bucci: Não nos perguntamos o que o presidente da República fez hoje... Isso é importante saber, mas nós nos perguntamos em que a vida do brasileiro mudou ou não mudou. Por essa razão, noticiamos na Voz do Brasil, por exemplo - o que muitos consideraram uma heresia -, o aumento da gasolina. Se a gasolina vai subir de preço, temos de noticiar. Quando no dia 27 de março o presidente da Caixa Econômica foi indiciado na Polícia Federal, a Voz do Brasil noticiou ao vivo, com um repórter na Polícia Federal e outro direto da Caixa Econômica Federal. A Voz do Brasil noticiou que o presidente da Caixa havia colocado o seu cargo à disposição. Isso seria impossível há algum tempo. Para nós é um dever, porque esses fatos mudam a expectativa do cidadão sobre os acontecimentos na Instituição, então ele precisa saber. A Voz do Brasil, das $19 \mathrm{~h}$ às $19 \mathrm{~h} 25$, é por lei encarregada de informar sobre o Poder Executivo. Então, temos de informar os fatos relevantes para a vida do cidadão e, por isso, noticiar sobre o aumento da gasolina e sobre a demissão de autoridades, por exemplo. Se não informamos sobre assuntos tão importantes quanto esses, o cidadão que não tem acesso a outro veículo de comunicação estará sendo agredido no seu direito à informação; ele não terá outro meio de saber desses acontecimentos. Essa discussão é interessante. Só para deixar registrado, sou a 
favor de que pelo menos se flexibilize o horário da Voz do Brasil. Esse regime de exibição em cadeia nacional, uma hora por dia em rede obrigatória, com horário fixo, tem uma justificativa muito discutível. Em estados como o Acre o programa vai ao ar, no horário de verão, às 16 horas, quando não há ninguém em casa. Se a Voz do Brasil é necessária, porque tem gente que só possui esse canal para se informar, deveria haver uma flexibilidade. Muitos dizem que a Voz do Brasil transmite informação de interesse público no rádio. Sob a nossa gestão, na Radiobrás, pode até ser, mas ao longo da história a Voz do Brasil carreou informação antipúblico, informação tirânica de regimes autoritários ou que se beneficiaram de recursos autoritários para desinformar o público e muitas vezes para tentar enganar o cidadão. Essa discussão precisa avançar, esta é a minha posição e já a tornei pública em outras ocasiões.

C \& E: Em termos de políticas públicas sobre o direito à informação, o que se pode ter como um rápido balanço dos avanços conquistados pela Radiobrás no período do governo Lula?

Eugênio Bucci: Isso vai ter de ser avaliado a posteriori. Posso dizer o seguinte: no âmbito das atividades e das atribuições da Radiobrás, nós recuperamos o patrimônio público. Por exemplo, recuperamos a Rádio Nacional do Rio de Janeiro que estava em ruína. Hoje a Rádio tem transmissor novo, um auditório restaurado e ali acontecem programas que fazem parte do roteiro cultural do Rio de Janeiro. Estamos instalando emissoras em parceria com universidades federais. Isso já gerou uma emissora que está em funcionamento, uma FM, em Belo Horizonte, em parceria com a Universidade Federal de Minas Gerais, e há

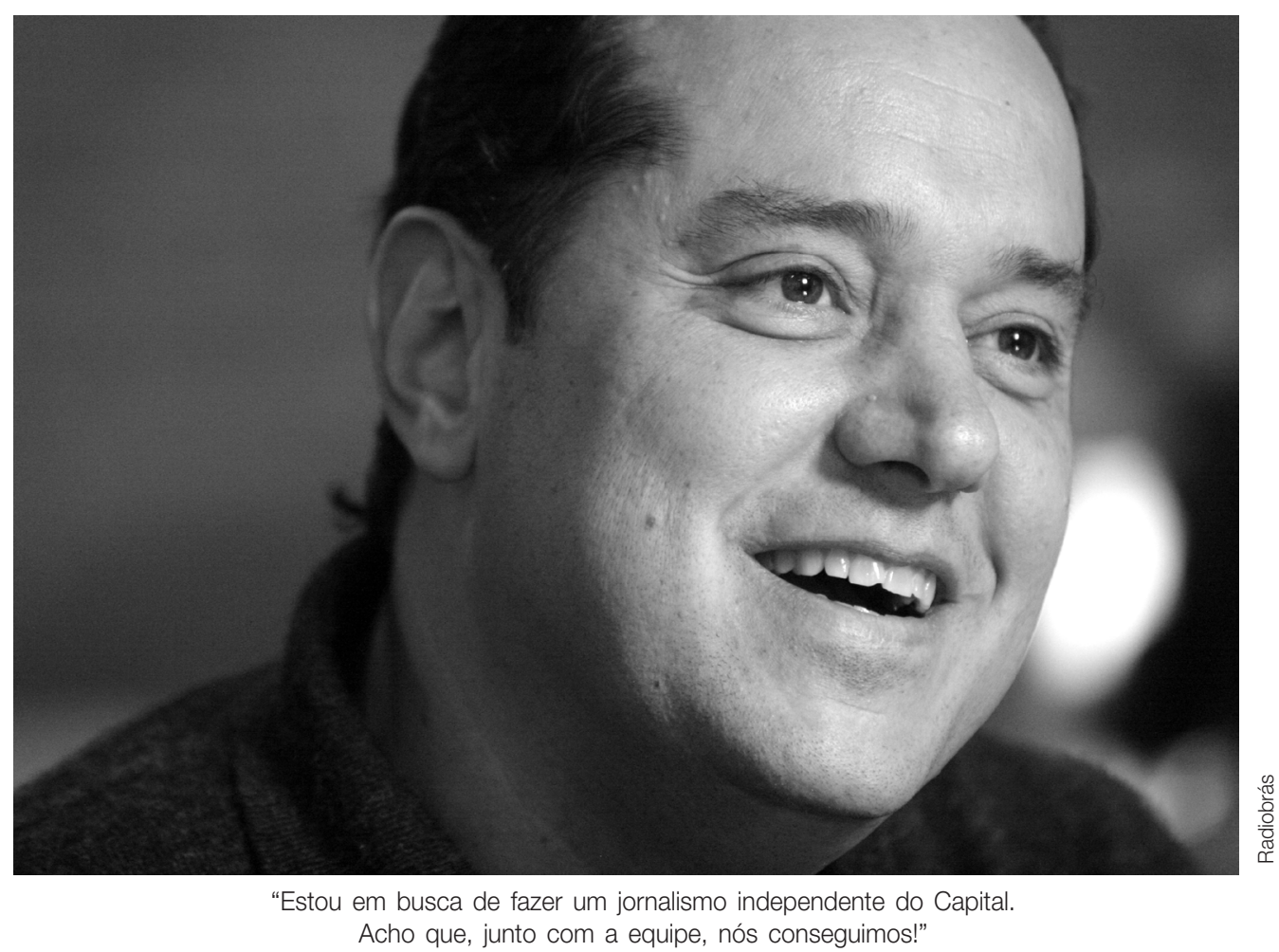


Informação, um bem público, direito do cidadão! • Roseli Fígaro

outras a caminho. Essas parcerias são interessantes porque garantem a autonomia de gestão das rádios pela universidade. As rádios têm uma programação noticiosa da Radiobrás de três horas por dia, mas toda a gestão da rádio, editorial inclusive, é autônoma. Avançamos também na filosofia de atendimento ao direito do cidadão. Esse atendimento tem o mérito implícito do governo, porque exerço um cargo de confiança do presidente da República, estou fazendo esse trabalho com o apoio do presidente da República, que teve coragem de ir até onde outros presidentes não foram. Há méritos da equipe que está comigo, mas há um mérito essencial do governo que deu apoio para que isso chegasse ao ponto em que chegou. Nós criamos, por exemplo, a Associação de Rádios Públicas no Brasil, a ARPUB. Até então as rádios públicas não estavam organizadas numa associação. É uma associação que caminha com dificuldade, mas já fez progressos. Trocam-se conteúdos, os gerentes e os diretores dessas emissoras se encontram, articulam-se. Houve a criação de uma Agência de Notícias de Rádio, cujo conteúdo pode ser acessado por todas as emissoras. Já temos entre 1.500 e 1.600 emissoras que todos os dias baixam conteúdo da Radioagência Nacional.

\section{C \& E: Gratuito?}

Eugênio Bucci: Gratuito. É um aspecto interessante, porque a mercadoria notícia é, nessas emissoras, diferenciada. Houve temor de que ao fazer isso, tanto na agência de rádio como na agência de textos e fotos, a Radiobrás pudesse apresentar concorrência às agências privadas. Isso não aconteceu, porque o que oferecemos é de uso generalizado, portanto não constitui diferencial competitivo para ninguém. As agências inclusive usam os nossos conteúdos, então elas não são prejudicadas. Nós contribuímos para que houvesse uma elevação geral da oferta e do nível da oferta, e as agências continuam competindo no diferencial que cada uma delas tem; mas a oferta geral melhorou e com isso melhorou também o trabalho das emissoras e a vida dos ouvintes. Hoje estamos totalmente pacificados com relação a isso.

C \& E: E a TV Brasil, canal integração, é outro feito?

Eugênio Bucci: Essa é uma história ainda muito incipiente e tenho o maior cuidado de falar sobre isso, porque é muito frágil... como se fosse uma criança de parto prematuro. Temos um acordo inédito entre os três poderes da República. Esse acordo foi trabalhado durante três anos. Durante um ano e meio, ficamos apenas discutindo a conceituação dessa iniciativa, fazendo planos editoriais muitas vezes com a orientação do Celso Nucci. Reunimos os dirigentes da comunicação da Radiobrás, do Senado, da Câmara e do Supremo Tribunal Federal, sempre com a presença dos embaixadores do Itamaraty, e vários deles participaram do planejamento da primeira fase de atividade da televisão do Estado brasileiro, destinada à América do Sul e um pouco à América Central, tendo como propósito facilitar a integração no nosso continente. Depois desse entendimento conceitual, da legitimação desse plano editorial, fizemos algumas coberturas em comum: primeiro, a do Fórum Social Mundial e, depois, a de 
algumas cúpulas que aconteceram em Brasília; tornamos disponível o sinal dessas coberturas. Já realizamos coberturas de cinco dias em espanhol, e várias emissoras do continente usaram esse material em seus noticiários. Depois disso, fizemos uma série de visitas, sempre orientados e conduzidos pelo Itamaraty, a cerca de 70 instituições na América Latina. Firmamos aproximadamente 35 acordos de troca de conteúdo, e temos na Radiobrás cerca de 500 horas de programação da América do Sul, vinda de quase todos os países. Nós temos parceiros de canais públicos, como o Canal Sete da Argentina, e também comunitários e privados, como um canal de Montevidéu; um canal da Amazônia, canais de instituições privadas e públicas, como a Fundação Roberto Marinho e a TV Cultura de São Paulo. Quase todos os países da América do Sul estão presentes. Já estamos transmitindo 24 horas por dia, 12 horas em português, 12 horas de programação em espanhol. Geramos um noticiário que é exibido semanalmente na Venezuela pela Telesul. Esse canal está no satélite e é reproduzido em alguns países da América do Sul. Além dos acordos de troca de conteúdos, estabelecemos mais de 70 acordos com operadoras de canal pago; destas, 10 já estão transmitindo 24 horas por dia em países diferentes. Em alguns lares da América do Sul e da América Central esse canal já pode ser sintonizado.

\section{C \& E: E no Brasil?}

Eugênio Bucci: No Brasil ele é transmitido seis horas por dia na NBR. Temos toda a programação em espanhol, para que os brasileiros possam ver alguma coisa da América do Sul, porque é curioso como não temos acesso à produção dos países vizinhos. Os canais pagos no Brasil não possuem um canal que reúna a programação sul-americana. Na NBR, que está presente no Brasil inteiro, transmitimos seis horas por dia de conteúdo de países diferentes da América do Sul; no mínimo, isso propicia contato, familiarização. A TV Senado tem horário para exibir essa programação; a TV Justiça e a TV Câmara também. Algumas TVs comunitárias, como a TV Comunitária de Belo Horizonte, já apresentam duas horas por semana dessa programação. A TV Brasil está no começo e a um custo quase zero. Temos o custo do aluguel do satélite, cujos recursos vêm dessa associação com o Itamaraty, com o Senado e com a Câmara; a nossa redação de 25 pessoas foi montada sem que houvesse aumento de quadros da Radiobrás, pois realocamos pessoas. Com relação ao quadro de pessoal, é bom registrar que assumi a Radiobrás com 1.149 funcionários e, hoje, ela conta com 1.164; a diferença é de 15 funcionários, ou seja, 1\%. No entanto, a Radiobrás produz incomparavelmente mais do que em 2002. Possui mais canais, mais emissoras de rádio, três além das quatro que existiam: uma é a Rádio Justiça, que passamos para o Supremo Tribunal Federal; outra é a emissora de Tabatinga, a qual inauguramos em maio; e a de Belo Horizonte, dirigida pela Universidade. Temos uma agência de notícias e uma série de outros serviços. Aumentamos de 18 para 24 horas a programação de quase todos os veículos da Radiobrás. Criamos a TV Brasil e o número de funcionários não foi alterado. A TV Brasil é um projeto que só pode vingar a médio prazo e, no futuro, talvez deva se tornar independente da Radiobrás, ser uma instituição formada pelos três 
poderes. Atualmente está incubada na Radiobrás; é um bebê prematuro que recebe uma proteção especial.

C \& E: Você começou me dizendo que quando aceitou o desafio de trabalhar na Radiobrás escreveu na Folha que iria tentar fazer um jornalismo independente do Capital. Já dá para passar um traço embaixo e fazer uma avaliação?

Eugênio Bucci: Isso precisa ser dito com toda cautela, porque não quero cometer o vitupério do elogio em boca própria. Mas o que preciso pensar comigo mesmo é uma questão pessoal que vem desse compromisso público de que lhe falei. Estou em busca de fazer um jornalismo independente do Capital. Acho que, junto com a equipe, nós conseguimos! Precisa haver melhora, uma nova formatação da própria empresa, o que nos impele a um outro patamar, e levaria a ajustes jurídicos. A Radiobrás precisa ter uma direção com um mandato, necessita da participação da comunidade nos seus conselhos. Esses ajustes terão de ser produzidos ao longo do tempo, mas fazemos ali um jornalismo interessante que cobre, além de Estado e de governo, a sociedade e, em especial, os movimentos sociais. Com muita dedicação, temos boas coberturas realizadas e temos sinais de que as coberturas são relativamente satisfatórias, pelo uso que esse material tem em todos os veículos de comunicação do Brasil. As revistas semanais usam menos, mas as emissoras de rádio e de televisão utilizam nossas imagens; os jornais impressos do Brasil inteiro também, e tenho retorno desses dados de várias maneiras. Outra coisa interessante é que algumas reportagens que publicamos têm merecido prêmios, e isso não era habitual na Radiobrás. Ganhamos alguns prêmios de grande significação dentro e fora do Brasil. Portanto, aconteceu alguma coisa ali, mas como eu disse a avaliação precisa ser posterior. No dia de hoje, 11 de maio de 2006, estou satisfeito, tenho uma boa relação com o resultado do trabalho que fiz e, até aqui, está valendo a pena.

Resumo: O jornalista Eugênio Bucci, presidente da Radiobrás, fala dos esforços para garantir o direito democrático à informação e das diferenças de objetivos entre a comunicação pública e a comunicação comercial. Apresenta os avanços conquistados em sua gestão, ressaltando a importância da Agência Brasil, a criação da Associação de Rádios Públicas e da TV Brasil, que tem por objetivo veicular conteúdos em português e espanhol para toda a América do Sul e parte da América Central.

Palavras-chave: informação, radiodifusão, comunicação pública, comunicação comercial, Radiobrás.
Abstract: Eugênio Bucci, journalist and president of Radiobrás, talks on the efforts to assure citizens their democratic right to information. Differences of objectives between public and commercial communication are presented. He describes advances conquered in his administration, highlighting the importance of Agência Brasil, the creation of Brazilian Association of Public Broadcasting Radios and of TV Brasil, which aims at transmitting contents in Portuguese and Spanish languages to all South America and to some areas of Central America.

Keywords: information, broadcasting, public communication, commercial communication, Radiobrás. 